\title{
HIV-1 Subtype Diversity and Prevalence of Primary Drug Resistance in a Single-Center Pediatric Cohort in Germany
}

\author{
Jennifer Neubert ${ }^{a}$ Nadja Michalsky ${ }^{a}$ Hans-Jürgen Laws ${ }^{a}$ Arndt Borkhardt ${ }^{a}$ \\ Björn Jensen ${ }^{c}$ Nadine Lübke ${ }^{b}$ \\ a Department of Pediatric Oncology, Hematology and Clinical Immunology, Center for Child and Adolescent Health \\ and ${ }^{b}$ Institute of Virology, Faculty of Medicine and ${ }^{\mathrm{C}}$ Department of Gastroenterology, Hepatology and Infectious \\ Diseases, Heinrich Heine University Düsseldorf, Düsseldorf, Germany
}

\section{Keywords}

HIV-1-infected children · Subtype · Drug-resistant

mutations $\cdot$ Mother-to-child transmission

\begin{abstract}
Objectives: Data on drug-resistant mutations (DRMs) in HIV1-infected therapy-naïve children are scarce. The aim of this study was to determine the HIV-1 subtype distribution and the prevalence of DRMs in therapy-naïve HIV-1-infected children who received routine care at the University Hospital Düsseldorf, Düsseldorf, Germany. Methods: Records of all HIV-1-infected children who received routine care between January 2005 and December 2015 were analyzed retrospectively. The collected data included demographics, clinical characteristics, CD4 cell count, viral load, HIV-1 subtype, and resistance genotype at baseline. Results: 83 HIV-1-infected children received routine care during the observation period. HIV-1 subtypes were available in $61 / 83$ patients (73.5\%) and baseline HIV-1 resistance in 24 (29\%). The prevalence of major DRMs was 29\% (21\% nucleoside reverse-transcriptase inhibitors [NRTIs], $12.5 \%$ non-NRTIs, and 4\% protease inhibitors). Minor mutations in the protease gene were common (58\%). Non-B subtypes were predominant (77\%). Conclu-
\end{abstract}

(C) 2017 S. Karger AG, Basel

\section{KARGER}

E-Mail karger@karger.com

www.karger.com/int sions: We report a predominance of non-subtype-B infections and a higher prevalence of DRMs compared to other pediatric cohorts from resource-rich settings. The difference in HIV-1 subtype distribution is due to the fact that a relevant proportion of pediatric patients in Germany are immigrants from high-prevalence settings in sub-Saharan Africa where non-B subtypes predominate.

(c) 2017 S. Karger AG, Basel

\section{Introduction}

The introduction of combined antiretroviral therapy (ART) has dramatically changed the course of infections with human immunodeficiency virus type 1 (HIV-1) in adults and children $[1,2]$. The use of ART in pregnancy and as prophylaxis in infants for the prevention of mother-to-child transmission (MTCT) has led to a pronounced reduction of vertical HIV-1 transmission, but a selection of drug-resistant mutations (DRMs) in infected infants is increasingly being reported $[3,4]$. Some HIV-1 subtypes and recombinants seem to accelerate the emergence of DRMs $[4,5]$. However, data on the clinical benefit of baseline resistance testing in children are currently lack- 
ing. German guidelines have recommended screening for baseline DRMs since 2006 and European guidelines (PENTA) have recommended screening in all therapynaïve children since 2009 [6, 7]. The prevalence of DRMs in therapy-naive and treated patients has been well-documented in adults but data on DRMs in therapy-naïve children are limited [8]. In US- and European-based cohort studies, the prevalence of drug resistance in therapynaïve children ranged between 9-30\% [8-12].

The prevalence of transmitted DRMs in HIV-infected therapy-naive adults in Germany was documented in the RESINA Study, and found to be $9.2 \%$ between 2001 and 2009 (nucleoside reverse-transcriptase inhibitors [NRTIs]) $5.8 \%$, non-NRTIs [NNRTI] $2.7 \%$, and protease inhibitors [PIs] 2.7\%) [13]. There are no data on DRMs and HIV-1 subtypes of HIV-1-infected children living in Germany.

The aim of this study was to determine the HIV-1 subtype diversity and the prevalence of DRMs in therapynaïve HIV-1-infected children who received routine care between January 2005 and December 2015 at the University Hospital Düsseldorf in Germany.

\section{Material and Methods}

Records of all HIV-1-infected children who received routine care between January 2005 and December 2015 at the Department of Pediatrics at the University Hospital Düsseldorf, were reviewed and analyzed retrospectively. The study was approved by the local ethics committee (internal study No. 4858).

The data included demographic profile (ethnicity, country of birth, sex, mode of transmission, perinatal antiretroviral exposure, age at diagnosis, year of HIV diagnosis), CDC stage, CD4 cell count, HIV-1 viral load, HIV-1 subtype and baseline genotypic resistance profile prior to the initiation of ART.

For genotypic resistance analysis, the HIV-1 RNA was isolated from EDTA plasma and analyzed for resistance mutations in the protease (PR) and reverse-transcriptase (RT) genes as previously described [14]. Sequencing was performed by classical Sanger sequencing analysis. Classification of HIV-1 subtypes was performed by sequence analysis of the PR/RT sequences with the NCBI genotyping tool (https://www.ncbi.nlm.nih.gov/projects/genotyping) or the COMET HIV-1 tool (https://comet.lih.lu). The detected drug resistance mutations were defined according to the Stanford Drug Resistance Database (http://hivdb.stanford.edu).

\section{Results}

\section{Study Cohort Characteristics}

A total of 83 patients were seen in the study period. Overall, $46 \%$ children were male and 54\% female. More than half $(66 \%)$ had one or both parents of African origin
Table 1. Demographic characteristics and HIV-1 subtype of the HIV-1-infected children

\begin{tabular}{|c|c|}
\hline Total number of children & 83 \\
\hline \multicolumn{2}{|l|}{ Sex } \\
\hline Female & 45 \\
\hline Male & 38 \\
\hline \multicolumn{2}{|l|}{ Ethnicity } \\
\hline Caucasian & 18 \\
\hline African & 55 \\
\hline Asian & 6 \\
\hline Other & 4 \\
\hline \multicolumn{2}{|l|}{ Country of birth } \\
\hline Germany & 46 \\
\hline Other & 30 \\
\hline Unknown & 7 \\
\hline \multicolumn{2}{|l|}{ Mode of transmission } \\
\hline Vertical & 77 \\
\hline Horizontal & 1 \\
\hline Unknown & 5 \\
\hline \multicolumn{2}{|c|}{ MTCT prophylaxis of any kind } \\
\hline Yes & 13 \\
\hline No & 70 \\
\hline \multicolumn{2}{|l|}{ Year of HIV diagnosis } \\
\hline Before 2005 & 46 \\
\hline $2006-2010$ & 22 \\
\hline 2011-2015 & 15 \\
\hline \multicolumn{2}{|l|}{ Age at diagnosis } \\
\hline$<1$ year & 31 \\
\hline $1-4$ years & 27 \\
\hline$\geq 5$ years & 20 \\
\hline Unknown & 5 \\
\hline \multicolumn{2}{|l|}{ HIV-1 group M subtype } \\
\hline $\mathrm{B}$ & 14 \\
\hline A1 & 3 \\
\hline CRF01_AE & 6 \\
\hline CRF02_AG & 13 \\
\hline CRF06_CPX & 5 \\
\hline CRF11_CPX & 1 \\
\hline CRF13_CPX & 2 \\
\hline $\mathrm{C}$ & 8 \\
\hline $\mathrm{G}$ & 4 \\
\hline $\mathrm{D}$ & 2 \\
\hline $\mathrm{F}$ & 3 \\
\hline Unknown & 22 \\
\hline
\end{tabular}

and $22 \%$ were Caucasians. In 46 patients (55\%), HIV-1 infection was diagnosed before 2005. The most prevalent mode of transmission was vertical infection (93\%) (Table 1). The majority of infected children (60\%) were born in Germany and did not receive prophylaxis to prevent MTCT, mainly due to the unknown HIV status of the mother during pregnancy. Thirteen patients (15\%) received some kind of prophylaxis to prevent MTCT (antepartum, intrapartum, or neonatal) but none of them had a viral load of $<40$ copies $/ \mathrm{mL}$ at birth. 
Table 2. Prevalence of drug-resistant mutations in 24 therapy-naïve HIV-1-infected children

\begin{tabular}{|c|c|c|c|c|c|c|c|c|c|c|}
\hline $\begin{array}{l}\text { Patient } \\
\text { No. }\end{array}$ & Sex & $\begin{array}{l}\text { Age at } \\
\text { baseline } \\
\text { resistance } \\
\text { testing }\end{array}$ & $\mathrm{CD} 4 / \mu \mathrm{L}$ & $\mathrm{VL} \mathrm{cp} / \mathrm{mL}$ & Subtype & NRTI & NNRTI & $\begin{array}{l}\text { PI } \\
\text { (major) }\end{array}$ & $\begin{array}{l}\text { PI } \\
\text { (minor) }\end{array}$ & $\begin{array}{l}\text { Perinatal ART } \\
\text { exposure or } \\
\text { a maternal } \\
\text { history of ART }\end{array}$ \\
\hline 1 & $\mathrm{~F}$ & 3 months & 637 & 999,000 & CRF13_CPX & none & none & none & L10I, K20I & no \\
\hline 2 & $\mathrm{~F}$ & 16 years & 363 & 9,934 & G & none & none & none & L10I, K20I & no \\
\hline 3 & M & 8 months & 1,946 & $4,089,367$ & CRF06_CPX & none & none & none & L10I & no \\
\hline 4 & M & 8 months & 1,032 & $3,600,000$ & $\mathrm{C}$ & none & none & none & $\mathrm{T} 74 \mathrm{~S}$ & no \\
\hline 5 & $\mathrm{~F}$ & 3 months & 3,058 & 906,490 & CRF02_AG & none & none & none & K20I & yes \\
\hline 6 & M & 6 weeks & 1,150 & $2,500,000$ & CRF01_AE & $\begin{array}{l}\text { M41L } \\
\text { D67N } \\
\text { K70R } \\
\text { V75M } \\
\text { M184V } \\
\text { L210W } \\
\text { L215Y }\end{array}$ & $\begin{array}{l}\text { K101E } \\
\text { V106M } \\
\text { E138A } \\
\text { G190A }\end{array}$ & none & $\begin{array}{l}\text { L10I } \\
\text { K20I }\end{array}$ & yes \\
\hline 7 & $\mathrm{~F}$ & 3 months & 2,889 & $3,197,440$ & B & D67DG & none & none & none & yes \\
\hline 8 & $\mathrm{~F}$ & 12 months & 363 & $>10,000,000$ & CRF02_AG & none & none & none & K20I & no \\
\hline 9 & M & 1 month & 2,545 & $1,069,635$ & A1 & A62V & none & none & none & yes \\
\hline 10 & M & 2 weeks & 564 & $>17,000,000$ & CRF02_AG & none & none & M46LM & K20I & yes \\
\hline 11 & $\mathrm{~F}$ & 10 years & & & CRF11_CPX & none & E138A & none & none & no \\
\hline 12 & $\mathrm{~F}$ & 8 years & 852 & 158,447 & $\mathrm{C}$ & none & none & none & none & no \\
\hline 13 & $\mathrm{~F}$ & 1 month & 3,732 & $>500,000$ & CRF02_AG & none & none & none & L10I, K20I & yes \\
\hline 14 & M & 13 years & 378 & 10,000 & A1 & none & none & none & none & no \\
\hline 15 & M & 6 years & 6 & 409,445 & CRF01_AE & none & none & none & L10I & no \\
\hline 16 & M & 9 months & 1,235 & 15,305 & CRF06_CPX & none & none & none & L10I, K20I & no \\
\hline 17 & M & 13 years & 354 & 8,513 & $\mathrm{C}$ & $\begin{array}{l}\text { K70EG } \\
\text { M184V }\end{array}$ & K103N & none & L24IV & no \\
\hline 18 & M & 8 years & 510 & 91,920 & CRF-02AG & none & none & unknown & unknown & no \\
\hline 19 & $\mathrm{~F}$ & 9 years & unknown & unknown & $\mathrm{C}$ & none & none & none & none & no \\
\hline 20 & M & 12 years & 828 & 17,261 & $\mathrm{~F} 1$ & none & none & none & L10LV & no \\
\hline 21 & M & 8 years & 258 & 41,446 & $\mathrm{C}$ & none & none & none & none & no \\
\hline 22 & $\mathrm{~F}$ & 2 years & 1,101 & 123,385 & CRF06_CPX & none & none & none & L10I, K20I & no \\
\hline 23 & M & 12 years & 351 & 264,792 & $\mathrm{~B}$ & K219KR & none & none & none & no \\
\hline 24 & $\mathrm{~F}$ & 2 years & 1,492 & 23,506 & CRF02_AG & none & none & none & none & no \\
\hline
\end{tabular}

VL, viral load (HIV-1 RNA); NRTI, nucleoside reverse-transcriptase inhibitor; NNRTI, non-NRTI; PI, protease inhibitor; ART, antiretroviral therapy.

Forty-one patients (49\%) started ART before 2005. Twenty-seven patients were therapy-naïve at their first visit at our center during the observation period. Fifteen patients started therapy at other centers during the observation period and were then referred to us.

\section{HIV Diversity}

The HIV-1 subtype was available in $73 \%(61 / 83)$ of the children (Table 1). Only 23\% (14/61) were infected with subtype B. Thus, non-B subtypes were most prevalent in this pediatric cohort, at $77 \%(47 / 61)$. The most frequently detected non-B subtypes were the circulating recombinant form CRF02_AG at 28\% (13/47), followed by subtype $\mathrm{C}$ at $17 \%(8 / 47)$. Regarding the children with available genotypic resistance testing before the initiation of
$\operatorname{ART}(n=24), 92 \%(22 / 24)$ harbored non-B subtype virus strains (Table 2).

\section{Drug-Resistant Mutations}

Results of baseline genotypic resistance testing were available in $24 / 83$ patients (29\%). The main reason for missing genotypic results at baseline was the initiation of ART before the implementation of routine resistance testing $(n=41)$. Further reasons for missing genotypes were therapy initiation at another center $(n=13)$ and unsuccessful amplification of the plasma samples $(n=2)$. The reason was unknown in 3 patients.

Baseline resistance testing revealed major HIV-1 DRMs in the virus strains of $7 / 24(29 \%)$ patients $(21 \%$ NRTIs, $12.5 \%$ NNRTIs, and 4\% PIs) (Table 2). Two pa- 
tients (\#6 and \#17) presented viruses with a dual class resistance, i.e., for NRTIs and NNRTIs. No patient was infected with a 3-drug-class-resistant variant. Besides major DRMs, several polymorphisms were observed in the RT gene of all therapy-naïve-infected children. DRMs were predominantly detected in 4/6 patients with neonatal or maternal ART exposure (\#6, \#7, \#9, and \#10) (Table 2 ). In 3 patients (\#11, \#23, and \#17), DRM-presenting viruses were found in children without a history of maternal ART (antepartum and intrapartum) or neonatal ART. One patient (\#17), a vertically infected boy diagnosed at the age of 13 years, harbored a virus with NRTI (K70EG, M184V) and NNRTI (K103N) mutations. His country of birth was Angola at a time when maternal ART and prophylaxis to prevent MTCT were not available. He had also previously been denied access to ART. A phylogenetic analysis of the HIV quasispecies of the child and the mother confirmed the vertical HIV-1 transmission; however, analysis of the mother's HIV-1 quasispecies did not present the DRMs detected in the child. Another patient (\#10) harbored a variant with a major PI mutation (M46L) at baseline. The medical history of this patient revealed maternal ART prior to pregnancy but no maternal ART during pregnancy and no neonatal ART to prevent MTCT. Overall, minor PI mutations were identified in the HIV-1 protease gene of 14 (58\%) patients, including the polymorphisms L10I and K20I, and the atypical mutation T74S.

\section{Discussion}

In this retrospective pediatric cohort study in Düsseldorf, Germany, the prevalence of HIV-1 infections with non-subtype-B variants was $77 \%$, thus showing a considerably higher frequency than in other pediatric cohorts in resource-rich settings, e.g., 11\% non-B variants in a Spanish cohort (1993-2010) and 3-35\% in pediatric US cohorts (2.7\% in The Bronx [2011] and 16.7\% in New York [2001-2002], NY, and 35\% on Rhode Island [1991-2012]) $[10-12,15]$. The higher frequency of non-subtype-B variants observed in our study was mainly due to the fact that more than half $(66 \%)$ of the patients had one or both parents of African origin where HIV-1 non-subtype-B variants are predominant [16].

With an overall frequency of $29 \%$, we observed a higher prevalence of drug resistance in therapy-naïve children than in other pediatric cohorts $[8-12,17,18]$. The prevalence rate of major DRMs in therapy-naïve children was $6.8 \%$ in $1998-2010$ in the UK and $13.6 \%$ in
1993-2010 in a Spanish cohort $(n=44)[9,10]$. Masquelier et al. [18] reported zidovudine resistance in $20 \%$ of the children born in France and enrolled in the ARNSEPF French national cohort in 1994-1999. In the US pediatric cohorts, the rate of DRMs was in the range of $12-24 \%[4,11]$. Overall, the usage of different mutation lists (e.g., from the International AIDS Society [IAS], Agence Nationale de Recherche sur le SIDA [ANRS], or Stanford HIV databases) for the identification of DRMs in the different studies presents a bias in the comparability of the prevalence of DRMs across different cohorts [19].

To date, there are no comparable data available from other pediatric cohorts in Germany. RT gene DRMs were the most prevalent mutations in our cohort $(21 \%$ NRTIs and $12.5 \%$ NNRTIs). In addition to the typically described DRMs in the RT gene, as detected in patients $\# 6$, \#9, and \#17, atypical amino acid substitutions at resistance-associated positions like D67G or K219R were also found (\#7 and \#23). Although their influence on drug susceptibility is not clearly defined, they were scored as DRMs according to the Stanford Drug Resistance Database (http://hivdb.stanford.edu). The RT mutation E138A detected in patient \#11 infected with the recombinant form CRF11_cpx is a polymorphic mutation in up to $5 \%$ of viruses, depending on the HIV-1 subtype [20]. Nevertheless, the presence of E138A prior to therapy may reduce the antiviral activity of rilpivirine, which has to be considered for the selection of an active drug regimen [21]. One patient (\#10) harbored the most likely transmitted PI mutation, M46L. This patient's mother did not receive any ART during pregnancy, did not disclose her HIV-1 status, and denied being HIV1-infected even after vertical HIV-1 infection was diagnosed in her child. Later, findings confirmed maternal ART prior to pregnancy and very poor adherence. Detailed information about the type of maternal ART prior to pregnancy was missing. M46L is described as a nonpolymorphic mutation selected for primarily by Indinavir, nelfinavir, fosamprenavir, atazanavir and lopinavir, leading to a reduced susceptibility to PI treatment [2224]. Two of the screened patients (\#6 and \#17) carried viruses with dual class resistance, to NRTIs and NNRTIs. Interesting was the finding of virus variants presenting the M184V mutation, which are characterized by impaired viral replication. The mother of patient \#6 received ART before and during pregnancy, but she had high viremia throughout pregnancy and at birth. Thus, the acquisition of the drug-resistant viruses in patient \#6 could be explained by MTCT. In contrast, the acquisi-
304

Intervirology 2016;59:301-306 DOI: $10.1159 / 000477811$
Neubert/Michalsky/Laws/Borkhardt/ Jensen/Lübke 
tion of DRMs in patient \#17 remains unclear. He was diagnosed at the age of 13 years and harbored NRTI and NNRTI mutations without a history of ART exposure. His country of birth was Angola, at a time when maternal ART and prophylaxis to prevent MTCT were not available, and previous ART had been denied. A phylogenetic analysis of the HIV quasispecies of the child and the mother confirmed the vertical HIV-1 transmission but the mother's virus did not harbor these DRMs. We speculate that the patient intermittently or transiently received ART with or without the knowledge of the mother. The mother consistently denied drug administration. This case emphasizes the importance of baseline resistance testing in every child regardless of their ART history.

Besides the major DRMs, we also identified a relevant proportion of patients carrying minor mutations, particularly L10I and K20I in the protease gene. L10I is a polymorphic mutation in the protease gene associated with reduced susceptibility to the protease inhibitors reported for subtype $B$ variants $[25,26]$. Regarding non-subtype-B variants, L10I is a frequent polymorphism [27]. K20I is the consensus amino acid in subtype G and CRF02_AG viruses and also other recombinants coding the subtype $\mathrm{G}$ in the protease, like CRF06_cpx or CRF13_cpx. The PIselected accessory mutation T74S detected in patient \#4 is also described as a polymorphism in most non-B subtypes [28].

The frequency of DRMs in therapy-naïve HIV-infected adults in Germany was well-documented in the RESINA Study. The study reported an average DRM prevalence of $9.2 \%$ in 2001-2009 (NRTIs 5.8\%, NNRTIs 2.7\%, and PIs 2.7\%) in North Rhine-Westphalia, Germany [13]. Moreover, subtype B was predominant (72\%) and recombinant forms were found in only $6 \%$ of the therapy-naïve patients. This difference in HIV-1 diversity compared to our pediatric cohort is mainly due to differences in ethnic origin and mode of transmission. In the RESINA adult cohort, $81 \%$ patients were of Caucasian origin, mainly German, $80 \%$ were male, and the mode of transmission was mainly sexual (51\% MSM). In our pediatric cohort, most patients or their parents were immigrants from Africa where HIV-1 non-subtype-B variants are predominant [16]. Due to the increasing accessibility to ART and strategies to prevent MTCT in sub-Saharan Africa, MTCT of HIV-1 is decreasing. However, among those who do become infected, the prevalence of DRMs, especially NNRTI resistance, is high. A recently published prospective observational study from South Africa demonstrated a high prevalence of NNRTI resistance

HIV-1 Subtype Diversity and DRMs in Children
(52\%) among infants who fail HIV-prophylaxis [29]. In another study from South Africa conducted in 2011, $56.8 \%$ of HIV-1-infected children harbored NNRTI, $14.8 \%$ harbored NRTI, and $1.3 \%$ harbored PI mutations [3]. Since a relevant percentage of new HIV-1-infected children seen at our center are immigrants from sub-Saharan Africa, this selection of DRMs being reported might have an impact on the prevalence of DRMs in the future.

Despite the limitations of this pediatric study on HIV1 subtype distribution and baseline drug resistance (its retrospective nature, small sample size, and sparse information on maternal drug history and maternal resistance profiles), it provides important information on the frequency of transmitted drug resistance in HIV-1-infected children. To date, it is the first study on HIV-1 subtype diversity and prevalence of DRMs in therapy-naïve HIV1-infected children receiving routine care at a center in Germany. This cohort study reveals a different HIV-1 subtype distribution with predominant non-B subtype infections versus the therapy-naïve HIV-1-infected adults in the RESINA cohort in Germany [13]. This difference is mainly attributed to the different ethnic backgrounds with a higher proportion of immigrants from sub-Saharan Africa in the pediatric cohort. Our results emphasize the importance of baseline screening for the presence of resistance-associated mutations in all HIV-1-infected children before the initiation of ART.

\section{Disclosure Statement}

There are no conflicts of interest.

$\begin{array}{ll}\text { References } & \text { Judd A, Doerholt K, Tookey PA, Sharland M, } \\ & \text { Riordan A, Menson E, et al: Morbidity, mor- } \\ & \text { tality, and response to treatment by children } \\ & \text { in the United Kingdom and Ireland with peri- } \\ & \text { natally acquired HIV infection during 1996- } \\ & \text { 2006: planning for teenage and adult care. } \\ & \text { Clin Infect Dis 2007,45:918-924. } \\ 2 & \text { Resino S, Bellon JM, Resino R, Navarro ML, } \\ & \text { Tomas Ramos J, de Jose MI, et al: Extensive } \\ & \text { implementation of highly active antiretroviral } \\ & \text { therapy shows great effect on survival and } \\ & \text { surrogate markers in vertically HIV-infected } \\ & \text { children. Clin Infect Dis 2004,38:1605-1612. } \\ 3 & \text { Kuhn L, Hunt G, Technau KG, Coovadia A, } \\ & \text { Ledwaba J, Pickerill S, et al: Drug resistance } \\ & \text { among newly diagnosed HIV-infected chil- } \\ & \text { dren in the era of more efficacious antiretro- } \\ & \text { viral prophylaxis. AIDS 2014,28:1673-1678. }\end{array}$

Intervirology 2016;59:301-306 DOI: $10.1159 / 000477811$ 
4 Persaud D, Palumbo P, Ziemniak C, Chen J, Ray SC, Hughes M, et al: Early archiving and predominance of nonnucleoside reverse transcriptase inhibitor-resistant HIV-1 among recently infected infants born in the United States. J Infect Dis 2007,195:1402-1410.

5 Megens S, Laethem KV: HIV-1 genetic variation and drug resistance development. Expert Rev Anti Infect Ther 2013,11:1159-1178.

6 Committee PS, Welch S, Sharland M, Lyall EG, Tudor-Williams G, Niehues T, et al: PENTA 2009 guidelines for the use of antiretroviral therapy in paediatric HIV-1 infection. HIV Med 2009,10:591-613.

7 Neubert J, Niehues T, Baumann U, Buchholz B, Notheis G, Wintergerst U, et al: Guideline for antiretroviral therapy of HIV-infected children and adolescents. Klin Padiatr 2012,224:98-110.

8 Rojas Sanchez P, Holguin A: Drug resistance in the HIV-1-infected paediatric population worldwide: a systematic review. J Antimicrob Chemother 2014,69:2032-2042.

9 Chakraborty R, Smith CJ, Dunn D, Green H, Duong T, Doerholt K, et al: HIV-1 drug resistance in HIV-1-infected children in the United Kingdom from 1998 to 2004. Pediatr Infect Dis J 2008,27:457-459.

10 de Mulder M, Yebra G, Navas A, Martin L, de Jose MI, Navarro ML, et al: Trends in drug resistance prevalence in HIV-1-infected children in Madrid: 1993 to 2010 analysis. Pediatr Infect Dis J 2012,31:e213-221.

11 Karchava M, Pulver W, Smith L, Philpott S, Sullivan TJ, Wethers J, et al: Prevalence of drug-resistance mutations and non-subtype B strains among HIV-infected infants from New York State. J Acquir Immune Defic Syndr 2006,42:614-619.

12 Rogo T, DeLong AK, Chan P, Kantor R: Antiretroviral treatment failure, drug resistance, and subtype diversity in the only pediatric HIV clinic in Rhode Island. Clin Infect Dis 2015,60:1426-1435.

13 Oette M, Reuter S, Kaiser R, Lengauer T, Fatkenheuer G, Knechten H, et al: Epidemiology of transmitted drug resistance in chronically
HIV-infected patients in Germany: the RESINA Study 2001-2009. Intervirology 2012,55:154-159.

14 Lubke N, Di Cristanziano V, Sierra S, Knops E, Schulter E, Jensen B, et al: Proviral DNA as a target for HIV-1 resistance analysis. Intervirology 2015,58:184-189.

15 de Mulder M, York VA, Wiznia AA, Michaud HA, Nixon DF, Holguin A, et al: HIV-1 drug resistance prevalence, drug susceptibility and variant characterization in the Jacobi Medical Center paediatric cohort, Bronx, NY, USA. HIV Med 2014,15:135-143.

16 Hemelaar J, Gouws E, Ghys PD, Osmanov S; WHO-UNAIDS Network for HIV Isolation and Characterisation: Global trends in molecular epidemiology of HIV-1 during 20002007. AIDS 2011,25:679-689.

17 Palumbo P, Holland B, Dobbs T, Pau CP, Luo CC, Abrams EJ, et al: Antiretroviral resistance mutations among pregnant human immunodeficiency virus type 1-infected women and their newborns in the United States: vertical transmission and clades. J Infect Dis 2001,184: 1120-1126.

18 Masquelier B, Chaix ML, Burgard M, Lechenadec J, Doussin A, Simon F, et al: Zidovudine genotypic resistance in HIV-1-infected newborns in the French perinatal cohort. J Acquir Immune Defic Syndr 2001,27:99-104.

19 Wagner S, Kurz M, Klimkait T; Swiss HIV Cohort Study: Algorithm evolution for drug resistance prediction: comparison of systems for HIV-1 genotyping. Antivir Ther 2015,20: 661-665.

20 Sluis-Cremer N, Jordan MR, Huber K, Wallis CL, Bertagnolio S, Mellors JW, et al: E138A in HIV-1 reverse transcriptase is more common in subtype $\mathrm{C}$ than $\mathrm{B}$ : implications for rilpivirine use in resource-limited settings. Antiviral Res 2014,107:31-34.

21 Theys K, Van Laethem K, Gomes P, Baele G, Pineda-Pena AC, Vandamme AM, et al: Subepidemics explain localized high prevalence of reduced susceptibility to rilpivirine in treatment-naive HIV-1-infected patients: subtype and geographic compartmentaliza- tion of baseline resistance mutations. AIDS Res Hum Retroviruses 2016,32:427-433.

22 Henderson GJ, Lee SK, Irlbeck DM, Harris J, Kline M, Pollom E, et al: Interplay between single resistance-associated mutations in the HIV-1 protease and viral infectivity, protease activity, and inhibitor sensitivity. Antimicrob Agents Chemother 2012,56:623-633.

23 Kempf DJ, Isaacson JD, King MS, Brun SC, $\mathrm{Xu}$ Y, Real K, et al: Identification of genotypic changes in human immunodeficiency virus protease that correlate with reduced susceptibility to the protease inhibitor lopinavir among viral isolates from protease inhibitorexperienced patients. J Virol 2001,75:74627469.

24 Rhee SY, Taylor J, Fessel WJ, Kaufman D, Towner W, Troia P, et al: HIV-1 protease mutations and protease inhibitor cross-resistance. Antimicrob Agents Chemother 2010,54:4253-4261.

25 Chang MW, Torbett BE: Accessory mutations maintain stability in drug-resistant HIV-1 protease. J Mol Biol 2011,410:756-760.

26 Mammano F, Trouplin V, Zennou V, Clavel F: Retracing the evolutionary pathways of human immunodeficiency virus type 1 resistance to protease inhibitors: virus fitness in the absence and in the presence of drug. J Virol 2000,74:8524-8531.

27 Turner D, Brenner B, Moisi D, Detorio M, Cesaire R, Kurimura T, et al: Nucleotide and amino acid polymorphisms at drug resistance sites in non-B-subtype variants of human immunodeficiency virus type 1. Antimicrob Agents Chemother 2004,48:2993-2998.

28 Deforche K, Silander T, Camacho R, Grossman Z, Soares MA, Van Laethem K, et al: Analysis of HIV-1 pol sequences using Bayesian Networks: implications for drug resistance. Bioinformatics 2006,22:2975-2979.

29 Kanthula R, Rossouw T, Feucht UD, Van Dyk G, Beck IA, Silverman R, et al: Persistence of HIV-drug-resistance among South African Children given nevirapine to prevent motherto-child-transmission. AIDS 2017;31:11431148 . 